
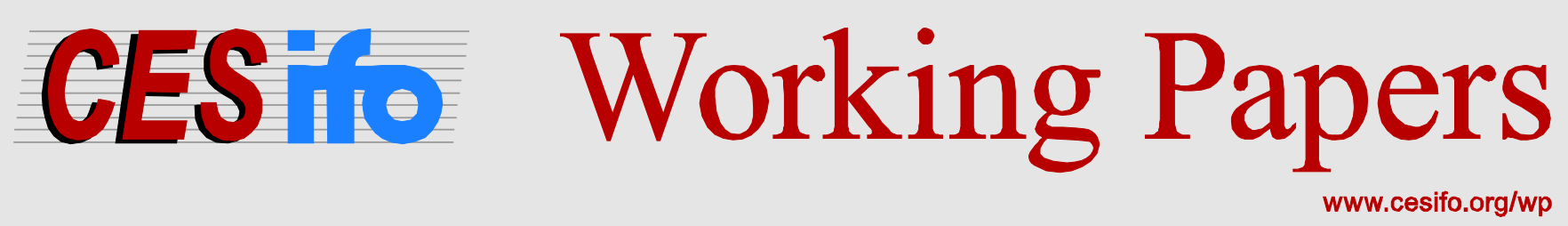

\title{
Pareto Improving Climate Policies: Distributing the Benefits across Generations and Regions
}

\author{
Michael Hoel \\ Sverre A.C. Kittelsen \\ Snorre Kverndokk
}

\author{
CESIFO WORKING PAPER NO. 5487 \\ CATEGORY 10: ENERGY AND CLIMATE ECONOMICS \\ August 2015
}

An electronic version of the paper may be downloaded

- from the SSRN website:

- from the RePEc website:

- from the CESifo website:

wWw.SSRN.com

www.RePEc.org

www.CESifo-group.org/wp 


\title{
Pareto Improving Climate Policies: Distributing the Benefits across Generations and Regions
}

\begin{abstract}
Most studies show that the present generation has to take the burden and reduce consumption to mitigate future climate change. However, significant climate change is due to a market failure, and corrections of market failures give possibilities of Pareto improvements. In this paper, we study the implication of Pareto improving climate policies. We use the representative consumer model RICE-10, which is a global model with different regions, to see how the benefits can be distributed across and within generations. The model shows that while the social optimum by definition is on the Pareto efficiency frontier, it is not necessary on the Pareto improving frontier, and that different combinations of present and future consumption along the Pareto improving frontier would give different combinations of capital investments and emissions. We find that all Pareto improving policies have higher total emissions than the social optimum when transfers are allowed. Without the possibility of transfers, total emissions may be lower than under the social optimum. Moreover, in this case carbon taxes differ substantially between regions for all Pareto improving policies.
\end{abstract}

JEL-Code: C630, D630, D990, H230, Q540.

Keywords: Pareto improvements, climate agreements, intergenerational distribution, intragenerational distribution.

\author{
Michael Hoel \\ Department of Economics \\ University of Oslo / Norway \\ mihoel@econ.uio.no
}

\author{
Sverre A.C.Kittelsen \\ Ragnar Frisch Centre for Economic \\ Research / Oslo / Norway \\ sverre.kittelsen@frisch.uio.no
}

\author{
Snorre Kverndokk* \\ Ragnar Frisch Centre for Economic \\ Research / Oslo / Norway \\ snorre.kverndokk@frisch.uio.no
}

*corresponding author

This paper is funded by the MILJØ2015 program at the Research Council of Norway. The authors are associated with CREE - the Oslo Centre for Research on Environmentally Friendly Energy - which is supported by the Research Council of Norway. Kverndokk is indebted to the support and hospitality of CES, Munich, while working on the paper. We also thank Jae Edmonds for discussion and comments. 


\section{Introduction}

Climate change has been on the political agenda for many years, and the United Nations Conference on Environment and Development (UNCED) in Rio in 1992 was the starting point for finding an international solution to lowering greenhouse gas (GHG) emissions that could give harmful environmental and social consequences. Even though the conference led to the Kyoto Protocol in 1997, the political attempts internationally to limit climatic change has not been successful, and the global $\mathrm{CO}_{2}$ emissions from fossil fuel combustion in 2010 were almost 50\% higher than in 1992 (IEA, 2012).

There are several reasons for the failure to establish an international agreement that gives significant reductions in GHG emissions. Problems include the public good character of the atmosphere that gives incentives for free-riding, the time profile of the climate problem where present generations have to take the burden for improving the climate of future generations (intergenerational equity), and the question of how to distribute the mitigation burden among countries today (intragenerational equity). While the problem of free-riding has been approached by using game theory to study stable coalitions of emission reducing countries (e.g., Barrett, 2005), the discussion of the other two reasons are mainly based on ethical reasoning. The intergenerational aspect is about burden sharing, i.e., how we should distribute the burdens within a generation, either within the generation living today or within future generations, see Kverndokk and Rose (2008), and will depend on different ethical views on distribution. On the other hand, the intergenerational equity discussion has mainly focused on the appropriate discount rate to use for climate change policy decisions, as the optimal level of abatement is very sensitive to the choice of discount rate. Discount rates are weights put on the future benefits of climate change policies in order to compare them to present and future costs. If we use a high discount rate (put a small weight on future generations), the mitigation burden for the present generation will be low, but the burden will be higher on future generations. ${ }^{5}$ The choice of the appropriate discount rate is an ethical issue and has been

\footnotetext{
${ }^{5}$ The intergenerational aspect of climate policies has been criticized by Rezai (2011) and Rezai et al. (2012). According to their argument, the main reason for the burden for present generations found in integrated assessment models (IAM) is that most studies use a hybrid constrained optimal path as the business-as-usual (BAU) path, where the emissions externality is partially internalized, but by assumption no mitigation is undertaken. Thus, the path is inefficient and the consumption level and the capital accumulation are both too high. A potential loss for current generations could therefore be substantially reduced and may even disappear, if an efficient BAU path is used.
} 
controversial for many years, see for instance, the Stern Review (Stern, 2007), and the subsequent discussion in e.g., Nordhaus (2007) and Weitzman (2007).

However, new research suggests that the appropriate discount rate may not be that important in climate change policy, as it may be possible to reduce the burden for the present generation without increasing future climate damages. Pareto improvements are possible when a market failure exists, and the Stern Review (2006, p. xviii) has called climate change "the greatest market failure the world has ever seen". Thus the possibility of climate policies that yield Pareto improvements should exist. The design of an international treaty where no generation will lose is the focus of Foley (2009). Such a treaty would eliminate the conflict of interests across generations that follows from the debate of the appropriate discount rate. If a social optimum exists that is beneficial to all generations, it should be possible to compensate the losers so that everybody would gain from the treaty. ${ }^{6}$ It is often claimed that the present generation needs to take the main mitigation burden, and that benefits of reduced climate change will occur in the future, i.e., the people that pay for mitigation are not the same people who enjoy the benefits of a better climate. Foley argues, however, that this does not have to be the case, and that the winners (future generations) can compensate the losers (the present generation) so that everybody gains from the treaty. What matters is the future generation's marginal value of a lower stock of atmospheric GHGs compared to an increase in conventional capital. If their valuation of the atmosphere is higher, it would be optimal for the present generation to substitute investments in conventional capital for mitigation capital without compromising their consumption. The valuation of the atmospheric stock of GHGs versus the real capital stock determines the composition of the stocks available for future generations, and correcting the global warming externality is the way to induce the optimal composition between the two capital stocks, i.e., we correct an inefficiency that would make more resources available for consumption. Thus, the resources needed for investments in mitigation can be taken from investments in conventional capital. In this way consumption does not have to be reduced for the present generation, and it may, therefore, not lose in utility terms if, as usually assumed, utility is a function of consumption. According to this, the discount rate is not directly important for the mitigation level of the present generation, but

\footnotetext{
${ }^{6}$ See also Broome (2012), pp. 43-48, Nordhaus (2008), pp. 179-181, and the latest IPCC assessments report (Kolstad et al., 2014, p. 227) for similar arguments, and the discussion on international Paretianism in Posner and Weisbach (2010).
} 
determines how the additional consumption from correcting the inefficiency will be distributed across generations.

One way to protect the present generation from reducing its consumption would be to finance mitigation efforts today by governmental debt that has to be redeemed by future generations. Future generations would pay for the mitigation by, e.g., paying higher taxes, but would gain by having a better environment. These transfers from the present to the future generations would be a Pareto improvement, as every generation will be at least as well-off as without a climate agreement. Such transfers have been the subject for analyses using overlappinggenerations (OLG) models. ${ }^{7}$ An early paper was Bovenberg and Heijdra (1998) that looked at Pareto improving mitigation when compensations are achieved by government borrowing in foreign capital markets and repaying the debt by taxing future generations. A similar model is used in Heijdra et al. (2006) that also designs a debt policy ensuring every generation gains. In a recent paper, Von Below et al. (2013) propose using the pension system as a transfer where young generations compensate old generations by paying their retirement pension as a pay-as-you-go pension. This system reduces the incentive to save and accumulate capital, and therefore consumption will increase. Other mechanisms are also proposed. Gerlagh and Keyzer (2001) study a "trust-fund" that entitles all members of present and future generations to an equal claim over natural resources. They show that this fund can ensure efficiency and protect welfare of all generations. Finally, Karp and Rezai (2012) show how asset pricing can give Pareto improvements when an environmental tax is introduced. Here, the productivity of capital depends on the state of the environment. As the capital is long-lived, the present generation can benefit from improved future productivity of the capital through asset pricing. Using appropriate transfers across generations, all generations may gain.

In this paper, we want to study the implication of Pareto improving climate policies. While such a principle is suggested as a way to reduce conflicts across generations, we are also interested in policies that will reduce conflicts within a generation, i.e., between countries or regions. Thus this paper is about inter- and intragenerational distributions. To do this, we use the representative consumer model to simulate Pareto improving policies. We introduce different regions to see how the benefits can be distributed across and within generations. While most economic analyses on distributional issues in climate change study either the

\footnotetext{
${ }^{7}$ A more general approach is Arrow and Levin (2009) that focuses on intergenerational transfers with an uncertain future population and when the size of the transferred resource can grow or shrink.
} 
inter- or the intragenerational perspective, our study adds to the literature by incorporating both aspects (see, e.g., Kverndokk et al., 2014).

The paper is organized as follows. In Sections 2-4 we introduce a simple theoretical model with representative individuals living at two different time periods; the present and the future. The present generation can affect the well-being of the future generation with its emissions and investments, as reduced emissions as well as higher investments will benefit them. We show that while the social optimum (obviously) is on the Pareto efficiency frontier, it is not necessary on the Pareto improving segment of this frontier. Moreover, different combinations of present and future consumption along the Pareto improving frontier will generally give different combinations of capital investments and emissions.

To study the Pareto improving climate policy in more detail, in Sections 5 and 6 we chose a numerical model that is similar in structure to the two-region two-period model described above, i.e., the RICE 2010 model (Nordhaus, 2010), where we aggregate the world into two regions; rich and poor. We derive Pareto improving efficient solutions in which no generation or region should loose from climate policy relative to its reference scenario. We explore four canonical cases that satisfy the condition that they are Pareto improving for all four groups today's rich, the future rich, today's poor, and the future poor. Policies that are Pareto improving can distribute benefits in an infinite number of ways across these four groups. Our four canonical scenarios explore circumstances in which no group is worse off than it would have been in the reference scenario, and one group captures all of the net benefits. Each of the four scenarios explores the implications of one group capturing all of the benefits, with all other groups no worse off. These scenarios are described in detail in Section 5.3. We run our four canonical cases for two different damage functions. In the first set of simulations we use the standard RICE-setup where damages reduce the output available to consumers. However, in the second set of simulations we also introduce damage directly into the utility functions, i.e., damages also have non-material impacts such as impacts on well-being and culture.

An important result from our numerical model is that the social optimum is not a Pareto improvement compared to a Business-As-Usual scenario (BAU). Moreover, we find that all Pareto improving policies have higher total emissions than the social optimum. Agreements where no agent within a generation will lose reduces conflicts of interest and hence may make 
it easier to reach an international treaty. However, the free rider problem may also undermine agreements that are Pareto improving.

Section 7 concludes with some policy recommendations.

\section{A two-period two-country model}

To illustrate the main mechanism of the numerical model to be presented in Section 5, we start with a very simple theoretical model of two periods and two countries (or regions), each having a constant population. Distributional issues within countries are ignored, so that each country in each period is illustrated by a representative agent.

Using subscript $t=1,2$ to denote period and superscript $k=a, b$ to denote country, the model is as follows:

$$
U_{t}^{k}=u\left(C_{t}^{k}\right) \text { utility }
$$

$$
Y_{t}^{k}=F^{k}\left(K_{t}^{k}, E_{t}^{k}\right) \quad \text { potential output; } E \text { is emissions of GHGs; } K \text { is capital }
$$

$$
S=\sum_{t} \sum_{k} E_{t}^{k} \quad \text { harmful stock of GHGs }
$$

$$
Q_{1}^{k}=Y_{1}^{k} \quad \text { output period } 1
$$

$$
Q_{2}^{k}=\Omega^{k}(S) Y_{2}^{k} \quad \text { output period 2, } \Omega^{k}(0)=1, \Omega^{k}(S)<0
$$

$$
C_{1}^{k}=Q_{1}^{k}-I^{k}+Z_{1}^{k} \quad \text { consumption period } 1, Z \text { is transfer }
$$

$$
C_{2}^{k}=Q_{2}^{k}+Z_{2}^{k} \quad \text { consumption period } 2
$$

$$
K_{2}^{k}=K_{1}^{k}+I^{k} \quad \text { where } K_{1}^{k} \text { is given ; } I \text { is investments }
$$




$$
\sum_{k} Z_{t}^{k}=0 \quad \text { alternatively assume all } Z_{t}^{k}=0
$$

While the equations and text above should not need much explanation, we will add some comments. In (2), all inputs except capital $K$ and fossil energy $E$ are assumed exogenous and, hence, ignored. Equations (3)-(5) imply that it is aggregated emissions from both countries over the two periods that are harmful, and this total $(S)$ only affects outputs negatively in period two. Equations (6)-(9) are accounting equations. Transfers between countries must sum to zero in each period. Alternatively, we could assume away such transfers altogether.

It is useful to start by describing the first-best social optimum. This follows from solving the following optimization problem:

Maximize

$$
W=\sum_{k} \phi_{1}^{k} U_{1}^{k}+R \sum_{k} \phi_{2}^{k} U_{2}^{k}
$$

Without loss of generality we may set $\phi_{1}^{a}=\phi_{2}^{a}=1$, implying that welfare is measured in period 1 utility for country $a$. The weights $R, \phi_{1}^{b}$ and $R \phi_{2}^{b}$ measure the weight given to country $a$ in period 2 and to country $b$ in period 1 and 2, respectively (all relative to country a in period 1).

The Lagrangian for this optimization problem is

$$
\begin{aligned}
& L=\sum_{k} \phi_{1}^{k} u\left(C_{1}^{k}\right)+R \sum_{k} \phi_{2}^{k} u\left(C_{2}^{k}\right) \\
& +\sum_{k} \mu_{1}^{k}\left[F_{1}^{k}\left(K_{1}^{k}, E_{1}^{k}\right)+Z_{1}^{k}-C_{1}^{k}-I^{k}\right] \\
& +\sum_{k} \mu_{2}^{k}\left[\Omega^{k}\left(\Sigma_{t} \Sigma_{j} E_{t}^{j}\right) F_{2}^{k}\left(K_{1}^{k}+I^{k}, E_{2}^{k}\right)+Z_{2}^{k}-C_{2}^{k}\right] \\
& -\gamma_{1} \Sigma_{j} Z_{1}^{k}-\gamma_{2} \Sigma_{j} Z_{2}^{k},
\end{aligned}
$$

and the FOC for the social optimum are $(k=a, b)$ 


$$
R \phi_{2}^{k} u^{\prime}\left(C_{2}^{k}\right)-\mu_{2}^{k}=0
$$

$$
\mu_{1}^{k} \frac{\partial F_{1}^{k}\left(K_{1}^{k}, E_{1}^{k}\right)}{\partial E_{1}^{k}}+\sum_{i} \mu_{2}^{i} \Omega^{k}(S) F_{2}^{i}\left(K_{2}^{i}, E_{2}^{i}\right)=0
$$

$$
\mu_{2}^{k} \Omega^{k}(S) \frac{\partial F_{2}{ }^{k}\left(K_{2}^{k}, E_{2}^{k}\right)}{\partial E_{2}^{k}}+\sum_{i} \mu_{2}^{i} \Omega^{k}(S) F_{2}^{i}\left(K_{2}^{i}, E_{2}^{i}\right)=0
$$

$$
-\mu_{1}^{k}+\mu_{2}^{k} \Omega^{k}(S) \frac{\partial F_{2}^{k}\left(K_{2}^{k}, E_{2}^{k}\right)}{\partial K_{2}^{k}}=0
$$

$$
\mu_{1}^{k}-\gamma_{1}=0
$$

Notice that the last two equations apply for the case with transfers, but not when transfers are ruled out.

Using (17)-(18), it follows from (12), (13) and (16) that

$$
\frac{\partial\left[\Omega(S) F\left(K_{2}^{k}, E_{2}^{k}\right)\right]}{\partial K_{2}^{k}}=\frac{\phi_{1}^{k} u^{\prime}\left(C_{1}^{k}\right)}{R \phi_{2}^{k} u^{\prime}\left(C_{2}^{k}\right)}=\frac{\gamma_{1}}{\gamma_{2}} .
$$

This implies that the consumption interest rate is the same in both countries. Notice that the equation above is simply the Ramsey rule for optimal investment, with the interest rate $r$ being defined as $\frac{\gamma_{1}}{\gamma_{2}}-1$. 
Together with (14) and (15) the equations above also give a common carbon price $q_{t}$ in each period:

$$
\begin{aligned}
& q_{1} \equiv \frac{\partial F_{1}^{k}\left(K_{1}^{k}, E_{1}^{k}\right)}{\partial E_{1}^{k}}=(1+r)^{-1} \sum_{i} \Omega^{i}(S) F_{2}^{i}\left(K_{2}^{i}, E_{2}^{i}\right) \\
& q_{2} \equiv \frac{\partial\left[\Omega^{k}(S) F_{2}^{k}\left(K_{2}^{k}, E_{2}^{k}\right)\right]}{\partial E_{2}^{k}}=\sum_{i} \Omega^{i}(S) F_{2}^{i}\left(K_{2}^{i}, E_{2}^{i}\right)
\end{aligned}
$$

These equations are simply the Pigovian tax rates for the two periods. The carbon price rises at the rate of interest, which is a standard result for stock pollutants when only the future stock matters for the environment.

If transfers were not allowed, interest rates and carbon prices would generally differ between countries. With the possibility of transfers, we want to maximize the total consumption in any period for a given total consumption in the other period. The allocation of these total consumption levels between countries is taken care of by appropriate transfers. Without the possiblity of transfers, distributional concerns must be addressed throught the choices of emission and investment levels. Interest rates and carbon prices will therefore generally differ between countries, since emissions and investments are no longer chosen only to maximize total consumption.

The reference scenario, or Business-As-Usual (BAU), is similar to the social optimum, but now each country does not take into account that its emissions have a negative effect on its future output and affect other countries. Hence, in the optimization problem both countris act as if $S$ were exogenously given. Equations (12), (13) and (16)-(18) are valid also for this case, but (14) and (15) are replaced by

$$
\frac{\partial F_{1}^{k}\left(K_{1}^{k}, E_{1}^{k}\right)}{\partial E_{1}^{k}}=0
$$

$$
\frac{\partial F_{2}^{k}\left(K_{2}^{k}, E_{2}^{k}\right)}{\partial E_{2}^{k}}=0
$$


The equilibrium of this reference scenario depends on all exogenous parameters and variables, and in particular on $R$ (country $a$ 's utility discount rate) and $R \phi_{2}^{b} / \phi_{1}^{b}$ (country $b$ 's utility discount rate). These parameters may be calibrated so that equilibrium transfers are zero $\left(Z_{1}^{a}=Z_{1}^{b}=0\right)$ and the equilibrium consumption interest rate $r=\frac{\gamma_{1}}{\gamma_{2}}-1$ is equal to the observed market rate of return. This same type of calibration can be used in an extended model of $N$ countries and $T$ time periods.

The equilibrium of this reference scenario gives values for all four utility levels, denoted by $\bar{U}_{t}^{k}$.

\section{Pareto improving deviations from the reference scenario}

Starting with the reference utilities, we consider four Pareto improvements; maximize the utlity of country $a$ today (period 1 ) and tomorrow (period 2), and country $b$ today and tomorrow. For all of these scenarios, three of the utility levels are kept unchanged at their reference levels $\bar{U}_{t}^{k}$, while the utility for the fourth combination sh (country $h$ in period $s$ ) is maximized. The Lagrangian to this problem is almost as it is for the social optimum; the only difference is that the first line in (11) is replaced by

$$
\sum_{k} \lambda_{1}^{k}\left[u\left(C_{1}^{k}\right)-\bar{U}_{1}^{k}\right]+\sum_{k} \lambda_{2}^{k}\left[u\left(C_{2}^{k}\right)-\bar{U}_{2}^{k}\right]
$$

where $\lambda_{s}^{h} \equiv 1$ and the Lagrange multipliers $\lambda_{t}^{k}$ for $t k \neq s h$ are endogenous shadow prices for the three constraints $u\left(C_{t}^{k}\right) \geq \bar{U}_{t}^{k}(t k \neq s h)$.

The solution to this problem is as before given by (12)-(18), except that in (12) and (13) the exogenous terms $\phi_{1}^{k}$ and $R \phi_{2}^{k}$ are replaced by $\lambda_{1}^{k}$ and $\lambda_{2}^{k}$, which are endogenous for the three combinations $t k \neq s h$. 
For a given reference scenario, emissions and other economic variables will typically depend on the choice of $s$ and $h$. A simple graphical illustration of this is given in the next subsection.

As an alternative to the analysis above, we could start with the same reference scenario but now assume no transfers when considering the Pareto improving changes in other variables. This will typically give a different outcome than with transfers, and a lower utility level $U_{s}^{h}$ than when transfers are permitted.

\subsection{A graphical illustration with one country}

Figure 1 illustrates the case with only one country, but two periods, i.e., the intergenerational distribution. The reference scenario is inefficient, and given by $N$ in the figure. The social optimum is given at $M$ on the Pareto efficient frontier, where the slope of the efficient frontier is equal to $-1 / R$. If $R=1$ (which combined with $\phi_{1}=\phi_{2}=1$ implies a utility discount rate of zero) the slope of the Pareto efficiency frontier will be -1 at $M$. For the more realistic case of a positive utility discount rate, we have $R<1$, so the slope of the efficient frontier is steeper than -1 .

In Figure $1 M$ is not a Pareto improvement from $N$. The Pareto improving points on the Pareto efficiency frontier are on the segment $P Q$. The analysis in the previous Section will give us the properties of the two ends of this line segment, i.e., at the points $P$ and $Q$.

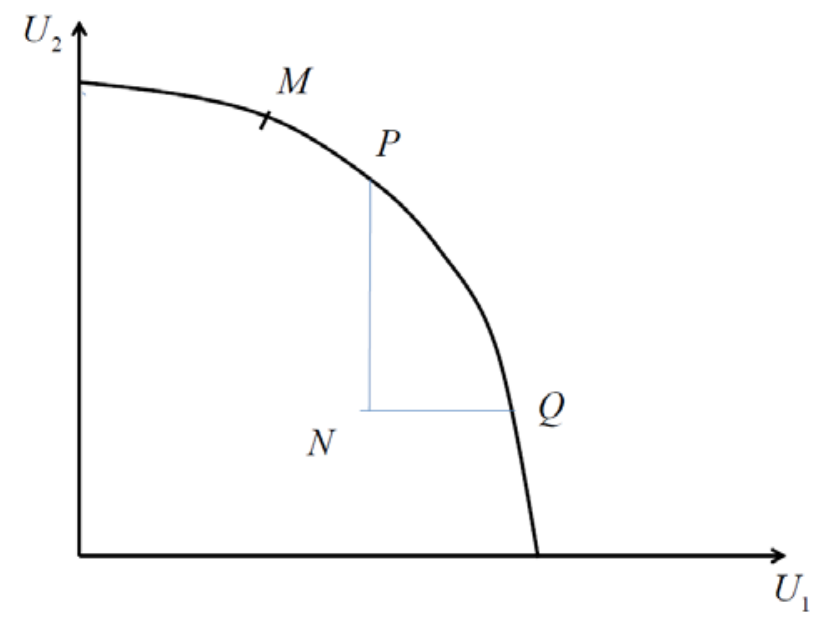

Figure 1: An illustration of Pareto optimal deviations from the reference scenario 
How do important variables (such as emissions in the two periods, investment, the interest rate, etc.) change as we move up and to the left along the Pareto efficiency frontier? The answer to this is not obvious. However, some intuition may be given: Moving up and to the left on the utility frontier means that consumption in period 1 is sacrificed in order to increase consumption in period 2. In this simple model this must imply higher investment $I$ in physical capital and/or reduced emissions $E_{1}$. Due to declining returns to both these types of investments, we expect these effects to occur for most functional forms. Under reasonable assumptions, some of the period 1 reduction in emissions will be crowded out by increased period 2 emissions. Nevertheless, total emissions over the two periods may decline, although the opposite may hold for some properties of the involved functions.

Given the conjectures above, we can conclude the following for the situation described in Figure 1: Pareto improving policies may have higher emissions (early and total) than the social optimum. Moreover, the difference in emissions is higher the more weight is given to period 2 compared to period 1. As we shall see in Section 6, these results are confirmed for total emissions in our numerical analysis, but early emissions are only in general reduced when one allows transfers between regions within each generation.

\section{Welfare weights in the social welfare function}

In the model with two countries and two periods, the Pareto efficiency frontier is a 4dimentional hyperplane. Each point on the interior part of this frontier corresponds to a particular combination of the parameters $R, \phi_{1}^{b}$ and $\phi_{2}^{b}$ in the social welfare function (10), with $\phi_{1}^{a}=\phi_{2}^{a}=1$. In the previous Section we illustrated the consequence of increasing $R$ in a one-country world, i.e., moving up and to the left on the utilty frontier in Figure 1. In this Section we keep $R$ constant, and discuss the consequences of increasing $\phi_{1}^{b}$ and/or $\phi_{2}^{b}$. It is useful to first consider a static version of the model, before returning to the full model in subsection 4.2. 


\subsection{Welfare weights in a one-period model}

Consider a one-period version of the model of Section 2, with production and emissions only in period 2. Thus, this streamlines the intragenerational perspective. For this model the social optimum is given by (13), (15) and (18). These equations may be rewritten as

$$
\begin{gathered}
u^{\prime}\left(C_{2}^{a}\right)=\phi_{2}^{b} u^{\prime}\left(C_{2}^{b}\right) \\
\Omega^{k}(S) \frac{\partial F_{2}{ }^{k}\left(K_{2}^{k}, E_{2}^{k}\right)}{\partial E_{2}^{k}}+\sum_{i} \Omega^{i}(S) F_{2}{ }^{i}\left(K_{2}^{i}, E_{2}^{i}\right)=0
\end{gathered}
$$

In this one-period model capital stocks in each country are exogenous. Hence, emissions in both countries are determined by (26) for $k=a, b$ and are independent of the welfare weight $\phi_{2}^{b}$. This welfare weight will only determine the distribution of consumption between the countries, and the necessary transfers to accommodate this distribution.

If transfers were ruled out, i.e., if there was a restriction $Z_{2}^{a}=Z_{2}^{b}=0$, emissions would obviously depend on the welfare weight $\phi_{2}^{b}$. Increasing this welfare weight would imply that the social optimum gave more consumption to country $b$ and less to country $a$. The only way to achieve this in the one-period model is to reduce $E_{2}^{a}$.

\subsection{Welfare weights in the two-period model}

We now return to the model described in Section 2, and study the consequences of increasing the welfare weight of country b, i.e. $\phi_{1}^{b}$ and $\phi_{2}^{b}$. (with $\phi_{1}^{a}=\phi_{2}^{a}=1$ ). In light of the result of the previous Section it is natural to ask whether it is possible to increase $\phi_{1}^{b}$ and $\phi_{2}^{b}$ in a manner that leaves emissions, investment and the interest rate unchanged. The answer is yes. To see this, consider first (12) and (17), which may be rewritten as

$$
u^{\prime}\left(C_{1}^{a}\right)=\phi_{1}^{b} u^{\prime}\left(C_{1}^{b}\right)
$$


If emissions and investments are to be unaffected by an increase in $\phi_{1}^{b}$, and utility is concave in consumption $\left(u^{\prime \prime}<0\right)$, this equation can be fulfilled by decreasing $C_{1}^{a}$ and increasing $C_{1}^{b}$ by the same amount when $\phi_{1}^{b}$ increases. Moreover, we may rewrite (10) as

$$
1+r=\frac{\partial\left[\Omega^{k}(S) F_{2}^{k}\left(K_{2}^{k}, E_{2}^{k}\right)\right]}{\partial K_{2}^{k}}=\frac{u^{\prime}\left(C_{1}^{a}\right)}{R u^{\prime}\left(C_{2}^{a}\right)}=\frac{\phi_{1}^{b} u^{\prime}\left(C_{1}^{b}\right)}{R \phi_{2}^{b} u^{\prime}\left(C_{2}^{b}\right)}
$$

For $r$ to be unaffected by the increase in $\phi_{1}^{b}$ and the accompanying decline in $C_{1}^{a}, C_{2}^{a}$ must decline so that $\frac{u^{\prime}\left(C_{1}^{a}\right)}{u^{\prime}\left(C_{2}^{a}\right)}$ is unaffected. Since both $C_{1}^{b}$ and $C_{2}^{b}$ increase (by the same amounts as the reductions in $C_{1}^{a}$ and $\left.C_{2}^{a}\right)$, the ratio $\frac{u^{\prime}\left(C_{1}^{b}\right)}{u^{\prime}\left(C_{2}^{b}\right)}$ will generally change. With a suitable change in the welfare weight $\phi_{2}^{b}$, the whole term $\frac{\phi_{1}^{b} u^{\prime}\left(C_{1}^{b}\right)}{R \phi_{2}^{b} u^{\prime}\left(C_{2}^{b}\right)}$ will nevertheless be unchanged as $\phi_{1}^{b}$ increases.

The reasoning above shows that we get a similar result as in subsection 4.1: It is possible to increase the welfare weights of country $b$ in a manner that redistributes consumption from country $a$ to country $b$ in both periods, but that leaves emissions, investment, output and the interest rate unchanged.

For a similar reason as given in subsection 4.1, this result will not hold if we rule out the possibilities of transfers between countries.

\section{Pareto improving climate policy in the RICE-model}

\subsection{The RICE-2010 model}

The RICE model (Nordhaus, 2010) is a regionalized version of the Dynamic Integrated model of Climate and the Economy (DICE) developed by Nordhaus (2008) ${ }^{8}$. It differs in a number

\footnotetext{
${ }^{8}$ The RICE-2010 model is implemented as an Excel optimization model and can be downloaded from http://www.econ.yale.edu/ nordhaus/homepage/RICEmodels.htm, along with supporting documentation. To
} 
of respects from the simple theoretical model of Section 2, notably in the dimensionality of time and countries. RICE-2010 is calibrated for 12 regions and 60 decades from 2000 to 2600. The decade 2001-2010 is, e.g., denoted by the representative year 2005. Only results for the first 10 or 20 decades are normally given substantive interpretations, with the remaining included to avoid ad hoc terminal conditions, with a constant savings rate from 2125 onwards. RICE also includes a backstop technology with an initially high but decreasing price, calibrated so that emissions decline rapidly after 2250 .

The per capita utility function in RICE-2010 is specified with a constant flexibility of marginal utility of 1.5 . The utility discount rate is $1.5 \%$ per annum, set to ensure that the real interest rate in the model is close to the real return on capital in real-world markets. The welfare function uses a modification of the Negishi calibrated weights that "equalize the period-by-period marginal utilities using the weighted average marginal utility, where each region's weights are the region's shares of the global capital stock in a given period” (Nordhaus, 2010, p. 2). The population is growing at an exogenous rate for each country.

Since the rich and poor regions live in different latitudes and have a different production structure, damages would not be symmetric. The damages are a function of temperature change in the atmosphere, which again depends on carbon concentrations in three reservoirs (atmosphere, biosphere and upper oceans, lower oceans). To reach steady-state equilibrium takes several centuries or more due to the ocean thermal lag. In the model, the calibrated parameters correspond to an equilibrium temperature-sensitivity coefficient of $3.2^{\circ} \mathrm{C}$ per $\mathrm{CO}_{2}$ doubling.

Production is modelled using a Cobb-Douglas production function with a capital output elasticity of 0.3 and labor output elasticity of 0.7 . Fuel input is proportionate to output but at country-specific rates that decline over time. In addition, emissions can be abated at a cost, implying that net production output must cover abatement costs in addition to damages, consumption, depreciation and net investments.

Our use of the RICE-2010 model follows the assumptions of Nordhaus (2010) with one major exception; since the size of the utility discount rate has been criticized by a number of authors and solved with the CONOPT solver. The GAMS model is available from the authors on request. 
(e.g. Stern, 2007), we have chosen to use $0.5 \%$ per annum in our base runs. This also means that results are shown more clearly. We have, however, included a number of sensitivity runs, one of which uses the original Nordhaus value of $1.5 \%$. Other sensitivity variations include setting all welfare weights to 1 , and introducing climate damages directly in the utility function instead of only as a net output loss.

\subsection{Aggregating into two regions and four time periods}

To be able to illustrate the results from the two-period two-country model discussed in Section 2, we aggregate the regions in the RICE model to two regions - Rich and Poor, and focus on two periods - Present and Future.

The Rich region consists of USA, EU, Japan, Russia, and other high income countries (OHI). The rest of the regions are aggregated into the Poor region: Eurasia, China, India, Middle East, Africa, Latin America and other non-OECD Asia. ${ }^{9}$

Also, to do the optimization over present and future welfare, we have aggregated time into the following periods:

- t0: 2001-2050

- $\quad t 1: 2051-2100$

- $\quad t 2: 2101-2150$

- $\quad t 3: 2151-2600$

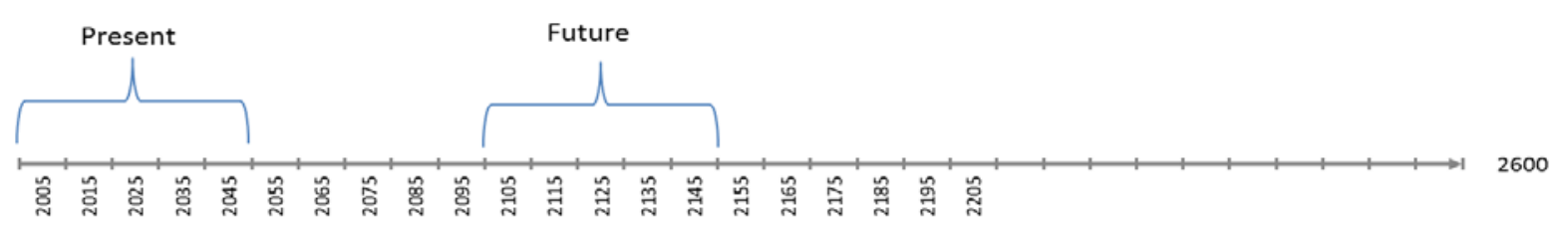

Figure 2: Illustration of the Present and Future within the time horizon of RICE

In the following, we name period to (the first half of the $21^{\text {st }}$ century) the present and period $t 2$ (the first half of the $22^{\text {nd }}$ century) the future. ${ }^{10}$

\footnotetext{
${ }^{9}$ The regions are aggregated based on their weights in the social welfare function.
} 


\subsection{The different scenarios}

In the simulations of the model, we work with the following scenarios. The first two scenarios are the standard scenarios used in the integrated assessment literature:

1. BAU: Business As Usual

2. OPT: Social optimum

Both of these assume that no direct consumption transfers are possible within each generation. In BAU, no abatement is allowed, while in OPT abatement is undertaken so as to maximize total welfare, i.e., the sum of discounted weighted utility.

In addition to the two scenarios above, we derive constrained optima in four dimensions where nobody loses in welfare terms compared to BAU: ${ }^{11}$

3. RICH20: Maximize the utility of the rich region today

4. RICH21: Maximize the utility of the rich region in the future

5. POOR20: Maximize the utility of the poor region today

6. POOR21: Maximize the utility of the poor region in the future

In the following, we also refer to the different scenarios as agreements. In these scenarios, the optimizing region receives all the benefits from the agreement, while the other regions and generation is just as well off as before.

All scenarios are run with two different specifications of the damage from climate change. In the main simulations we use the standard RICE-setup where climate change reduces the output available to consumers. While in the sensitivity analyses we also introduce damage directly into the utility functions, i.e., climate change also have non-material impacts such as amenity.

\footnotetext{
${ }^{10}$ To aggregate within a time period, we summarize the present value of a variable based on the social discount rate.

${ }^{11}$ While we only report results for $t 0$ and $t 2$, we constrain on $t 1$ and $t 3$ as well, such that no generation will lose.
} 
In the scenarios, we introduce consumption transfers within a generation. However, we also report the cases where transfers are not possible.

\section{Simulation results}

The simulations using RICE show the quantitative difference between the different scenarios. We distinguish between the case where transfers between regions are allowed within each period, and the case where such transfers are not allowed.

A region has two possibilities to affect the output of the future generations; with GHG emissions that have an impact on future damage and, therefore, output and/or welfare, and through real investments that increase future capital stocks and, therefore, production possibilities. In the model, real investments decisions are taken via the savings rate, i.e., the share of the net output (net of climate damage) that is not consumed, but used for real investments. $^{12}$

In the RICE model, the only possibility to affect other regions at the same time period is via transfers, as there is no trade or other interactions between regions in the model. However, as time periods are aggregated in our model, and covers a range of 40 years, GHG emissions also has an impact on other regions within the same generation.

\subsection{Consumption transfers}

We first study the case with consumption transfers. The optimizing region, i.e., the rich or poor region today or in the future, maximizes its utility level, given that the other regions (today and in the future) should not be worse off than in BAU. Figure 3 shows the development in temperatures in this situation. Not surprisingly, the temperature is highest in the BAU scenario as there is no abatement. Less obvious is the result that the temperature is lowest in the social optimum, while the Pareto improvement scenarios are in the middle. This indicates that the social optimum, as traditionally defined, is not Pareto improving compared with the BaU scenario. We hence have a situation as illustrated in Figure 1, where the social optimum point $M$ is not on the Pareto improving part of the Pareto efficiency frontier.

\footnotetext{
${ }^{12}$ Thus, the savings rent is endogenous. However, for technical reasons, the savings rent is exogenous from 2170 in the simulations.
} 


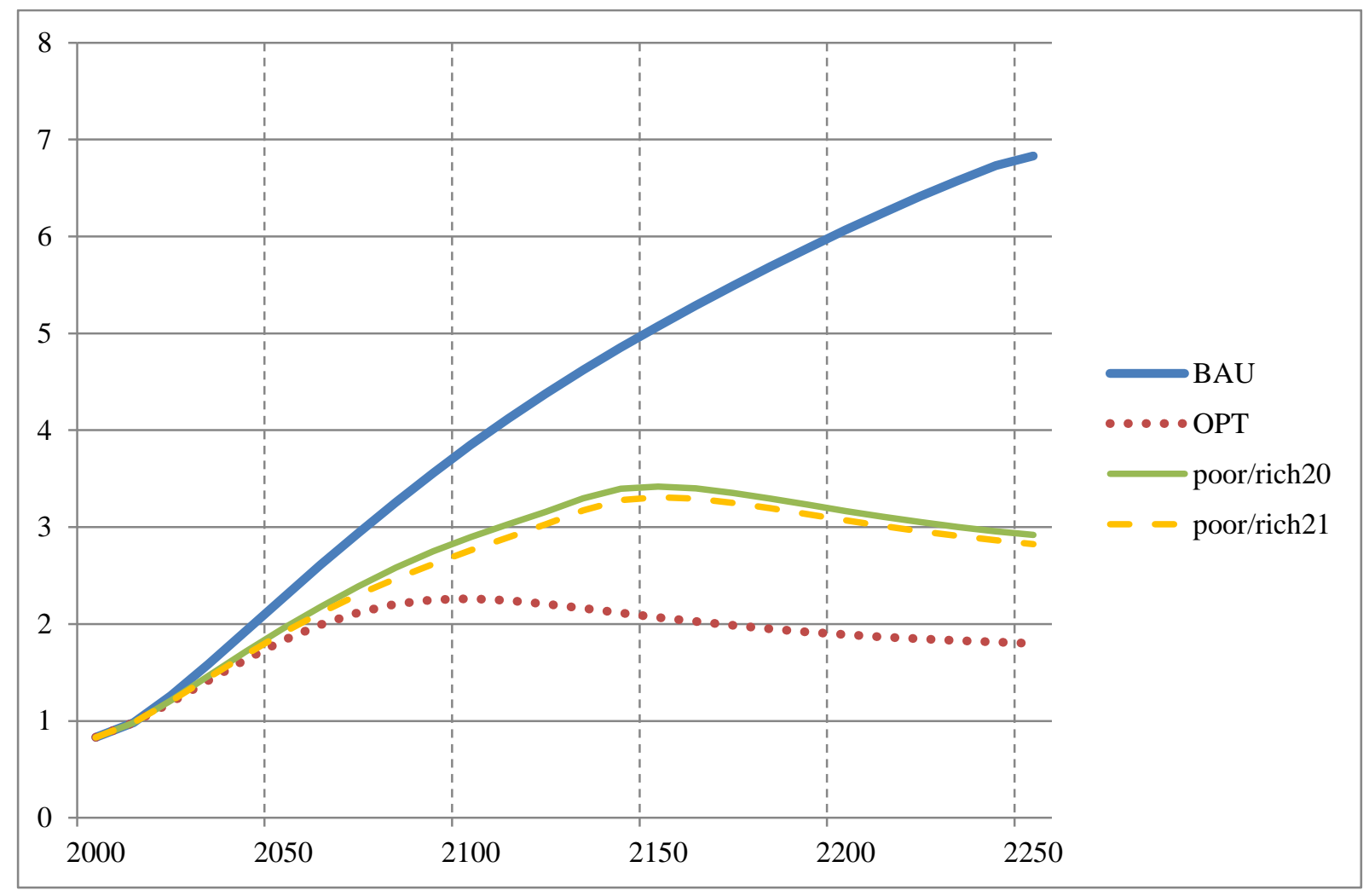

Figure 3: Development of global mean temperature compared to the pre-industrial temperature under the different scenarios. Consumption transfers. $\rho=0.5$ p.a.

As explained in Section 2, abatement and temperature only depends on whether we are maximizing with respect to the present or future generations. When transfers are allowed, it makes no difference to abatement and temperature whether we are maximizing with respect to the rich or poor region, as transfers make it optimal to maximize the total consumption in any period for a given total consumption in the other period. The allocation of these total consumption levels between countries is taken care of by appropriate transfers. In these scenarios, transfers today are invariably from rich to poor countries, while transfers in the future depend on the region whose utility is maximized.

Figure 3 also reveals that optimizing outcomes for the present generation (POOR/RICH20) give slightly higher temperatures than optimizing for the future generation (POOR/RICH21). Future generations have larger impacts from climate change than the present generation, and will therefore like to reduce emissions more when they get the extra benefit from an agreement. When present generations optimize, they grasp the extra benefit themselves, and only do the necessary abatement to make future generations no worse off. 
The time paths for the carbon tax under the Pareto improving scenarios are illustrated in Figure 4. We know from Section 2 that when transfers are allowed, carbon taxes will be equalized across regions. ${ }^{13}$ However, the carbon tax will depend on whether we are optimizing with respect to the present of future generations. Not surprisingly, carbon taxes for most of the present century are higher when we maximize welfare for the future generation rather than for the present generation.

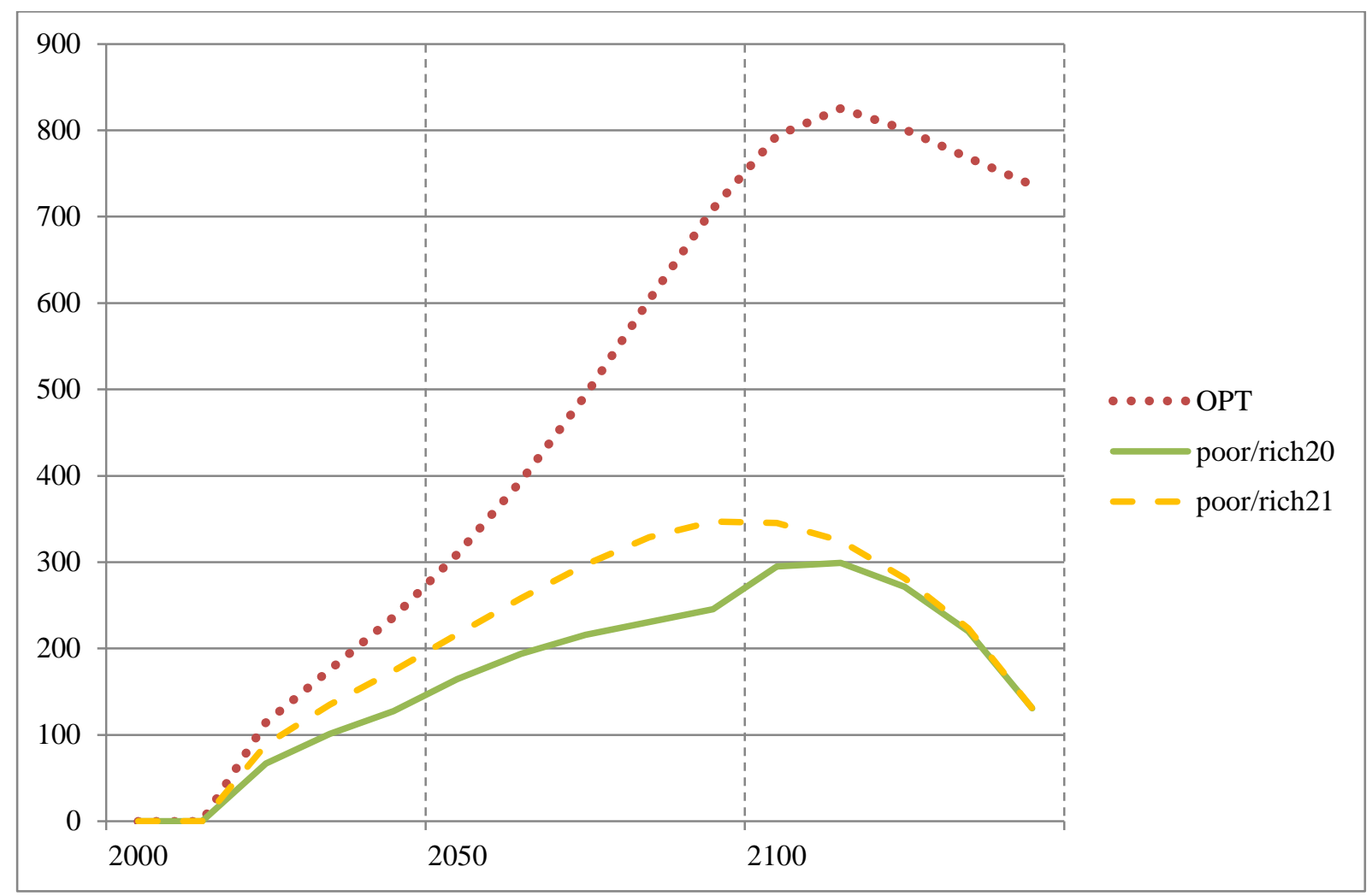

Figure 4: Carbon taxes (2005 USD per ton carbon) under the different scenarios.

Consumption transfers. $\rho=0.5$ p.a.

\subsection{No transfers}

Next, we turn to the case without transfers. Figure 5 shows the development in temperatures in this situation. Also in this case, the temperature is highest in the BAU scenario as there is no abatement. The temperature is lowest in the social optimum from the beginning of the next century, while it is actually higher than when optimizing for rich countries (RICH2O and RICH21) up to that point in time. Thus, there is more abatement in the Pareto improving

\footnotetext{
${ }^{13}$ In our actual calculations, the carbon taxes are not fully equalized. The reason is that we do not optimize for each country, but for the aggregated region, and within each region the distribution of the consumption transfers follow the weights used in the aggregation. In a simulation where we have utility transfers on the regional level instead, we get equalized carbon taxes. The taxes shown in Figure 4 are averages of the tax rates in the two regions.
} 
scenarios in this century if the rich countries optimize. The reason is that climate policy under the social optimum is used as a redistribution instrument when transfers are not allowed, and rich countries, therefore, have to abate more. The poor region values consumption increases relatively more than environmental impacts compared to the rich region. Thus, they are more willing to increase their consumption at the expense of a worse climate than the rich region is.

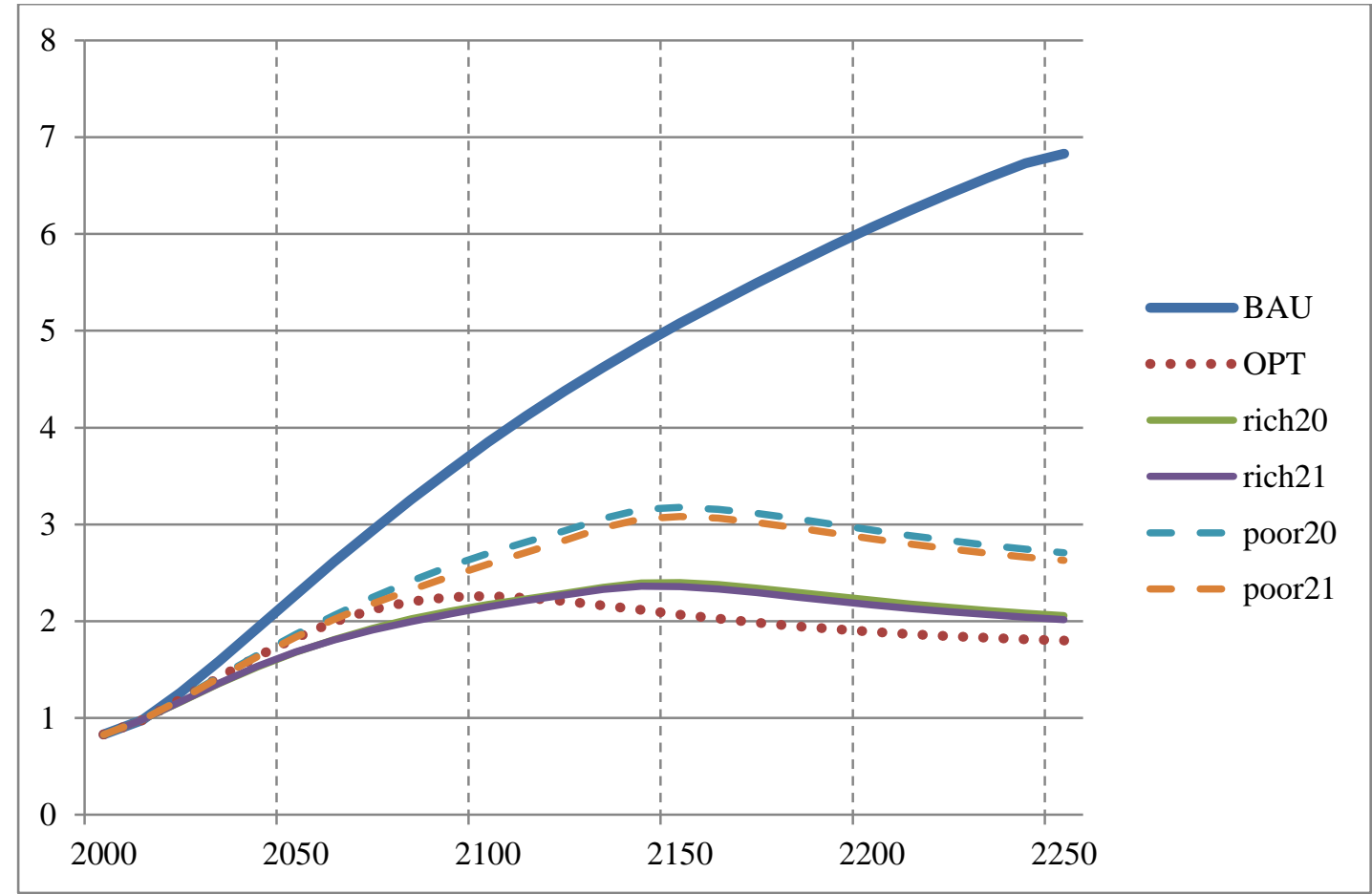

Figure 5: Development of global mean temperature compared to the pre-industrial temperature under the different scenarios. No transfers. $\rho=0.5$ p.a.

Also, as seen from Figure 5, the scenarios RICH20 and RICH21 follow each other closely, and so do the scenarios POOR20 and POOR21. Thus, it does not matter much if it is the rich region today or in the future that maximizes, or alternatively, if it is the poor region today or in the future that does the maximization. The reason for this is that the rich region in the next generation benefits from capital accumulation in the rich region today, and therefore, prefers the poor region to abate. Thus, they share preferences with the rich region today.

Comparing Figure 5 with Figure 4, we see that there is less warming without transfers than with. As mentioned above, climate policy is used as a redistribution instrument when transfers 
are not allowed. Introducing transfers, means that less abatement has to be done to satisfy the distributional requirements, see also Eyckmans et al. (1993).

Figure 6 shows the time paths of the carbon tax for the two scenarios where we maximize the welfare of future generations (we find a similar picture when the welfare of present generations are maximized). We see that the carbon price is much higher in the poor region than the rich under RICH21. We also see that if the poor region optimizes, the result is turned around, with a much higher tax in the rich region. The optimizing region, thus, puts a higher burden on the other region and grasps the net benefit itself. Note also that as the carbon tax differs across regions, neither of these scenarios give cost effective solutions as is the case with the social optimum (OPT). The carbon taxes can be very high, up to almost $\$ 950$ per ton carbon in the non-optimizing region by the end of this century, but the development is bump shaped, even if the optimal temperature levels start falling during the $22^{\text {nd }}$ century. The reason is that the backstop technology has an exogenous technological development that makes abatement cheap when this technology becomes available.

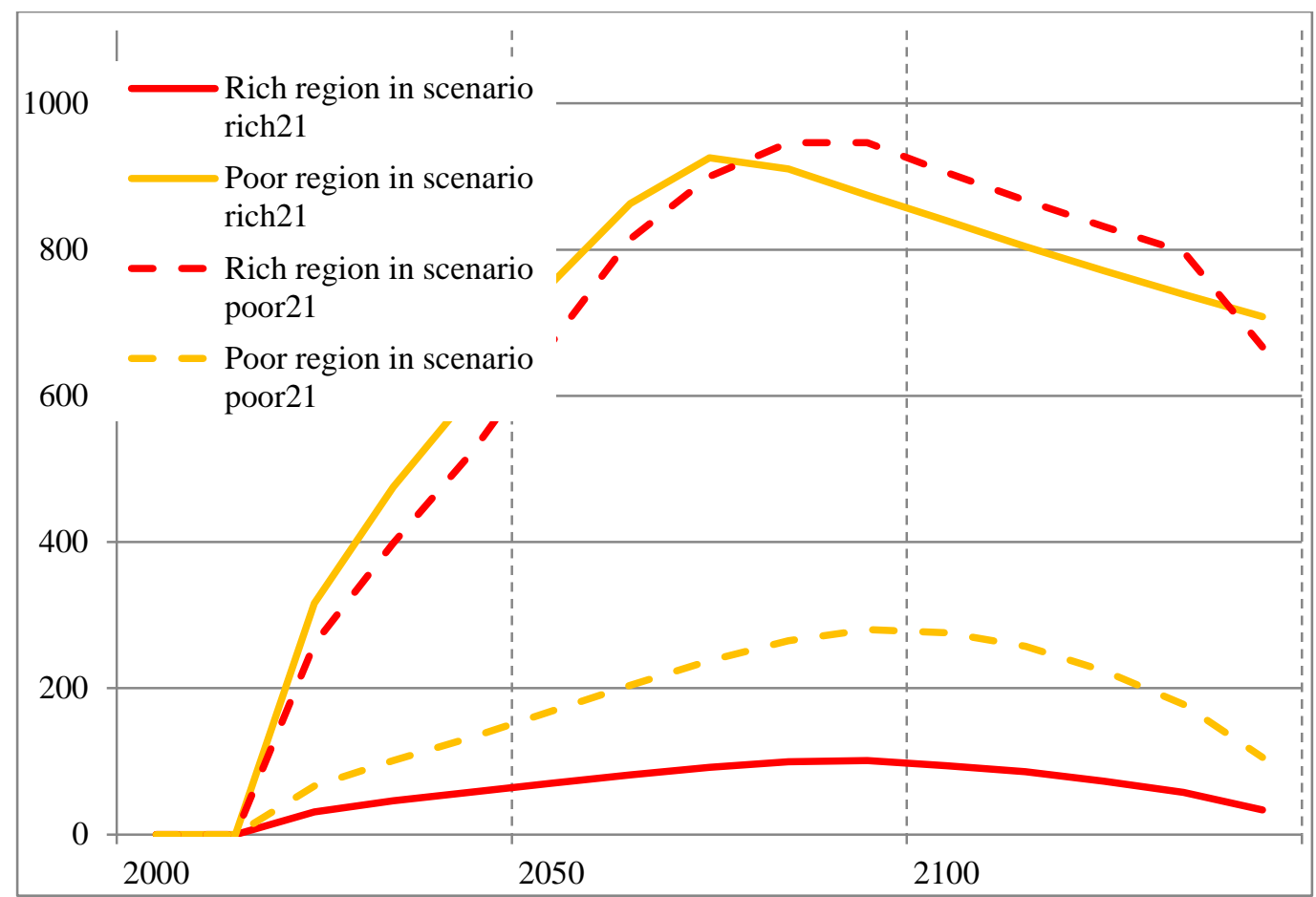

Figure 6: Carbon taxes (2005 USD per ton carbon) under two Pareto improvement scenarios. No transfers. $\rho=0.5$ p.a. 


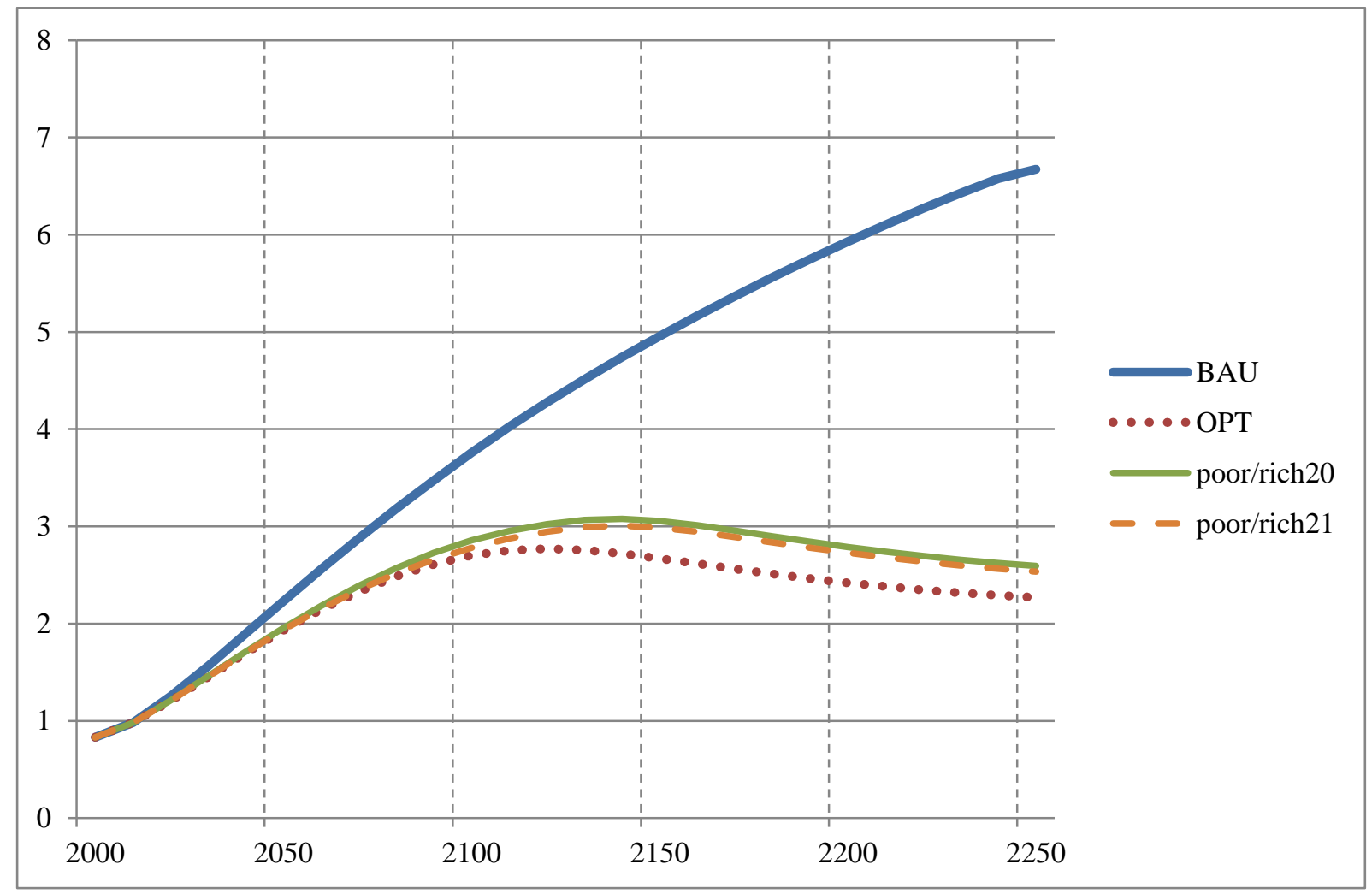

Figure 7: Development of global mean temperature compared to the pre-industrial temperature under the different scenarios. Consumption transfers. $\rho=1.5$ p.a.

\subsection{Sensitivity analyses}

\subsubsection{The utility discount rate}

We now study the impacts of setting the utility discount rate equal to $1.5 \%$ p.a., i.e., the same as in the original RICE model. Below, we present the graphs for the case with consumption transfers, but the alternative with no transfers show similar developments. Not surprisingly, Figure 7 shows that a higher discount rate gives more global warming under social optimum; we care less about future warming. The effect of increasing the utility discount rate from $0.5 \%$ to $1.5 \%$ is to increase the temperature increase with $0.5^{\circ} \mathrm{C}$ by 2100 .

For the Pareto improvement scenarios, we actually get the opposite result; the optimal temperature will be lower with a utility discount rate of $1.5 \%$ than with $0.5 \%$. To understand this, we know that these scenarios depend on the BAU scenario, as the BAU constraints the solutions. With a higher utility discount rate, the social discount rate is higher, which makes investments less profitable; future outcomes count less. Lower investments mean lower 
production, and, therefore, emissions in the BAU scenario. This mechanism gives lower production in the Pareto improvement scenarios.

While not shown in the figure, the carbon tax for the Pareto improving scenarios is steadily increasing over the next 200 years. The reason is that abatement is postponed with higher utility discounting, thus a higher carbon tax is necessary also at the end of the $22^{\text {nd }}$ century. The turning point for the carbon tax comes later than for the case with a lower utility discount rate.

\subsubsection{Non-material damages}

Integrated assessment models use a highly aggregated representation of damages. IPCC has criticized this representation, and claims that it may understate aggregate damages from climate change (Kolstad et al., 2014). To respond to this criticism and to study the impacts of harm that do not directly reduce available output, such as human amenity, we have introduced damages into the utility function, and calibrated it as a reduction in utility representing about $0.5 \%$ reduction in GDP per degree Celsius temperature increase.

With this experiment, climate damage is much higher than before, hence increasing the difference between the BAU case and the Pareto efficient cases. Not surprisingly, as seen from Figure 8, with this higher climate damage the optimal temperature is lower all scenarios compared with our previous cases. However, the two degree target, as outlined by the Copenhagen Accord, ${ }^{14}$ will still not be reached by 2100 in the scenarios where the present generation optimizes (Rich/Poor20). Another interesting result is that the differences in the Pareto improving scenarios where the present generation and the future generation optimize have increased (compare with Figure 3). The reason for this is that the benefits from mitigation increases with higher damage, and this benefit mainly accrues to the future generations. Thus, they would prefer an agreement with higher mitigation for the present generation. Carbon taxes need to be higher as there is more mitigation in this scenario. The taxes will reach its maximum size (more than $\$ 1000$ per ton carbon in some scenarios) by the middle/end of this century as mitigation has to be increased fast.

\footnotetext{
${ }^{14}$ The document from the 15th session of the Conference of Parties (COP 15) to the United Nations Framework Convention on Climate Change that took place in Copenhagen in 2009.
} 


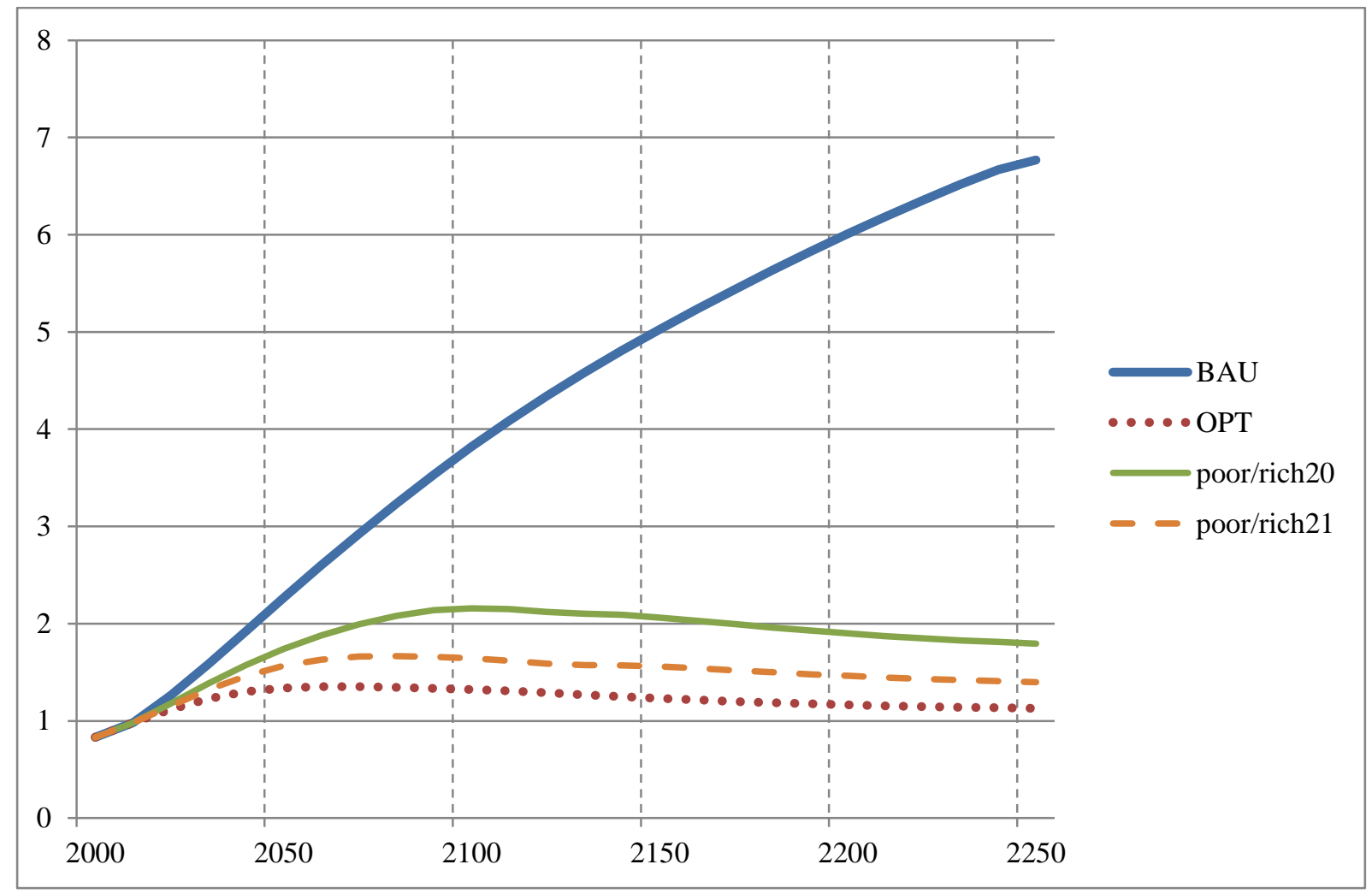

Figure 8: Development of global mean temperature compared to the pre-industrial temperature under the different scenarios. Damage enters directly in the utility function. Consumption transfers. $\rho=0.5$ p.a.

\subsubsection{Negishi weights}

The RICE model uses Negishi weights to compare the different utilities of the regions in the social welfare function. These weights do not explicitly take into account equity aspects and are set to make the current distribution ptimal in the model, so that the optimization without climate change (BAU) would not divert much from the present real world situation initially. Thus, the richer regions have higher welfare weights than poor regions to remove the impact of higher marginal welfare of consumption in poor countries. This implies that the present income (consumption) distribution is optimal, i.e., the weighted marginal utility of income is the same in all countries. Thus, by using Negishi weights, we accept diminishing marginal utility of income for intergenerational choices, but not for intragenerational choices. Without such weights, it would be optimal to redistribute income so that marginal utility of consumption is equal across regions as part of the climate policy (see, e.g., Stanton, 2011). 
As the use of Negishi weigthts is controversial from an equity perspective, we have run a set of simulations setting the welfare weights equal to one for both regions. As seen from Figure 9, this would reduce emissions compared to when Negishi weights are used in all scenarios. The reason is that poor regions will be harder hit by climate change, and when their welfare counts more, it will be optimal to mitigate more. We also see that the difference between the scenarios where present and future generations optimize increases. This is again due to the higher impact future damages have on poor countries. As these count more, future impacts will count more in the social welfare function.

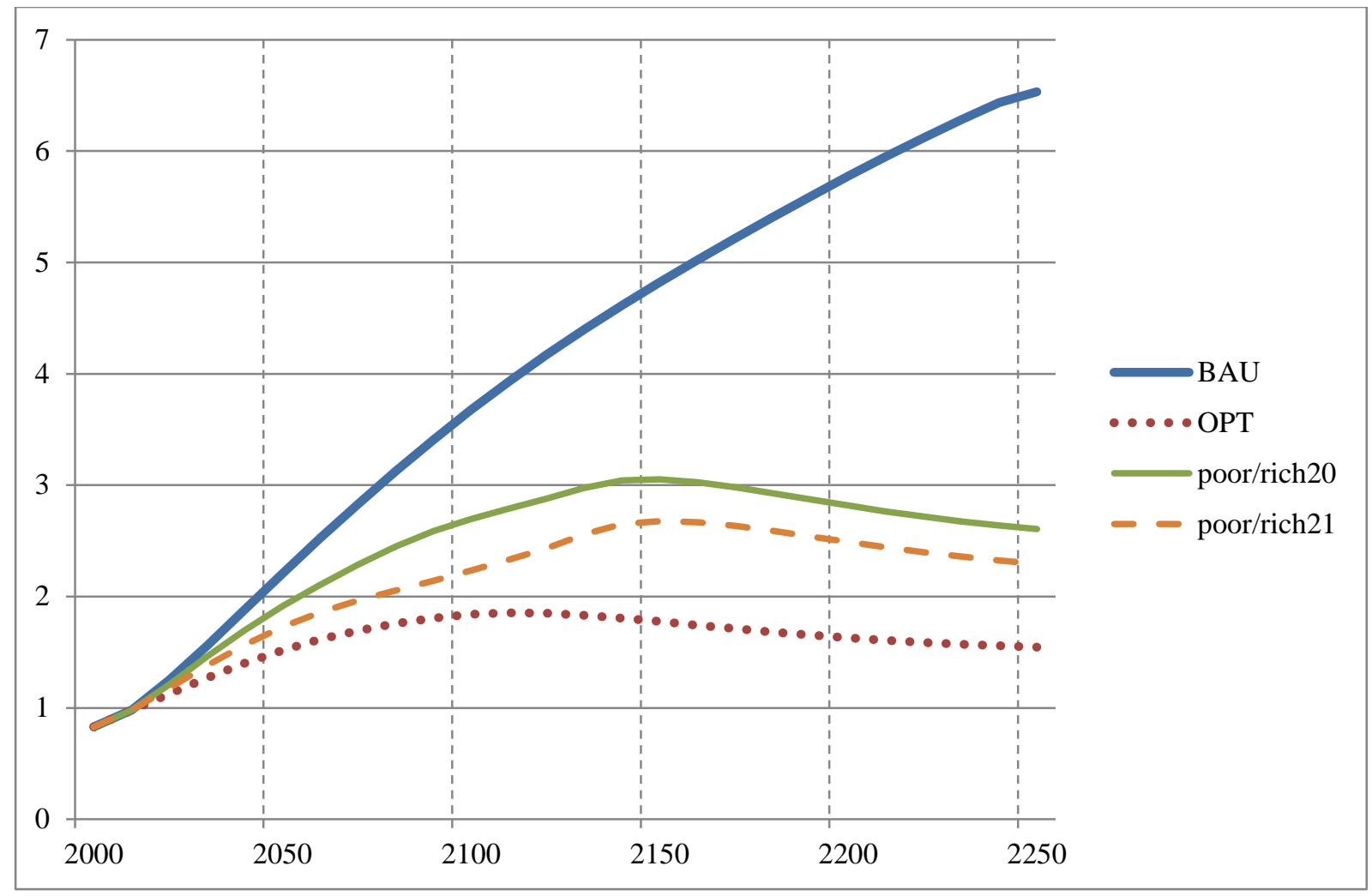

Figure 9: Development of global mean temperature compared to the pre-industrial temperature under the different scenarios. Equal welfare weights. Consumption transfers. $\rho=0.5$ p.a.

\section{Conclusions}

The focus above has been the implications of international climate agreements where no generation or region would lose compared to doing nothing. Most studies show that the present generation has to take the burden and reduce consumption to mitigate future climate change. However, significant climate change is due to a market failure, and corrections of 
market failures create possibilities for Pareto improvements. It is therefore in principle possible to construct such agreements. We illustrate this with a two-period two-region model, and show some general characteristics of such agreements.

To study some of the implications of Pareto improving climate policies, we use the representative consumer model RICE-10 model, which is a global model with 12 geopolitical regions. These are aggregated in our simulations to poor and rich countries. The distribution of welfare between the present and future generation is determined by real capital investments and GHG emissions. We show that while the social optimum is on the Pareto efficiency frontier, it is not necessary on the Pareto improving frontier, and that different combinations of present and future consumption along the Pareto improving frontier would give different combinations of capital investments and emissions.

Pareto improving policies have higher total emissions than the social optimum, indicating that the two degree target may not be a Pareto improvement compared with $\mathrm{BaU}$. The outcomes of the policies depend significantly on when and who gets the efficiency gain, and also on what is assumed about consumption transfers across regions. If the present generation gets the efficiency gain, climate change will be higher than if the gain is given to future generations. The larger the damage from climate change, and the more they count in the social welfare function, the larger this difference will be.

An important message to take home from our study is that a focus on Pareto improving agreements is likely to have more success than an international treaty that is designed so that some generation must sacrifice its own welfare for another generation. However, even Pareto improving agreements may be difficult to achieve, partly due to the free rider problem. 


\section{References}

Arrow, K. J. and S. A. Levin (2009): Intergenerational resource transfers with random offspring numbers, PNAS - Proceedings of the National Academy of Sciences of the United States of America, 106(33): 13702-13706.

Barrett, S. (2005): The theory of international environmental agreements, Chapter 28 in K.-G. Mäler and J. R. Vincent (eds.): Handbook of Environmental Economics, Volume 3: 1457-1516. Elsevier B.V.

Bovenberg, A. L. and B. J. Heijdra (1998): Environmental tax policy and intergenerational distribution, Journal of Public Economics, 67(1): 1-24.

Broome, J. (2012): Climate matters, ethics in a warming world, Norton.

IEA (2012): $\mathrm{CO}_{2}$ emissions from Fuel Combustion, IEA, Paris.

Eyckmans, J., S. Proost and E. Schokkaert (1993): Efficiency and distribution in greenhouse negotiations, Kyklos, 46(3): 363-397.

Foley, D. K. (2009): The Economic Fundamentals of Global Warming, in Harris, J. M. and N. R. Goodwin (eds.): Twenty-First Century Macroeconomics: Responding to the Climate Change, chapter 5, Edward Elgar Publishing: Cheltenham and Northampton.

Gerlagh, R. and M. A. Keyzer (2001): Sustainability and the intergenerational distribution of natural resource entitlements, Journal of Public Economics, 79(2): 315-341.

Heijdra, B. J., J. P. Kooiman and J. E. Ligthart (2006): Environmental quality, the macroeconomy, and intergenerational distribution, Resource and Energy Economics, 28: 74104.

Karp, L. and A. Rezai (2012): The Political Economy of Environmental Policy with Overlapping Generations, CUDARE Working Papers 1128, University of California, Berkeley, Department of Agricultural \& Resource Economics.

Kolstad C., K. Urama, J. Broome, A. Bruvoll, M. Cariño Olvera, D. Fullerton, C. Gollier, W. M. Hanemann, R. Hassan, F. Jotzo, M. R. Khan, L. Meyer, and L. Mundaca (2014): Social, Economic and Ethical Concepts and Methods. Chapter 3 in: Edenhofer, O., R. Pichs-Madruga, Y. Sokona, E. Farahani, S. Kadner, K. Seyboth, A. Adler, I. Baum, S. Brunner, P. Eickemeier, B. Kriemann, J. Savolainen, S. Schlömer, C. von Stechow, T. Zwickel and J. Minx (eds.), Climate Change 2014: Mitigation of Climate Change. Contribution of Working Group III to the Fifth Assessment Report of the Intergovernmental Panel on Climate Change, Cambridge University Press, Cambridge, United Kingdom and New York, NY, USA.

Kverndokk, S., E. Nævdal and L. Nøstbakken (2014): The trade-off between intra- and intergenerational equity in climate policy, European Economic Review, (69): 40-58.

Kverndokk, S. and A. Rose (2008): Equity and justice in global warming policy, International Review of Environmental and Resource Economics, 2(2): 135-176. 
Nordhaus, W. D. (2007): A Review of the Stern Review on the Economics of Climate Change, Journal of Economic Literature, 45(3): 686-702.

Nordhaus, W. D. (2008): A Question of Balance: Weighing the Options on Global Warming Policies, Yale University Press, New Haven, CT.

Nordhaus, W. D. (2010): Economic aspects of global warming in a post-Copenhagen environment, PNAS, 107(26): 11721-11726.

Posner, E. A. and D. Weisbach (2010): Climate Change Justice, Princeton University Press.

Rezai, A. (2011): The Opportunity Cost of Climate Policy: A Question of Reference, Scand. J. of Economics, 113(4): 885-903.

Rezai, A., D. F. Foley and L. Taylor (2012): Global warming and economic externalities, Economic Theory, 49(2): 329-351.

Stanton, E. A. (2011): Negishi welfare weights in integrated assessment models: the mathematics of global inequality, Climatic Change, 107: 417-432.

Stern, N. (2007): The Economics of Climate Change: The Stern Review, Cambridge University Press, Cambridge, UK.

Von Below, D., F. Denning and N. Jaakkola (2013): Consuming more and polluting less today: intergenerational efficient climate policy, paper presented at the EAERE conference in Toulouse, 26-29 June, 2013.

Weitzman, M. (2007): A Review of the Stern Review on the Economics of Climate Change, Journal of Economic Literature, 45(3): 703-724. 